Bulletin of Spanish Studies (2014), 91:5, 773-792.

DOI: $10.1080 / 14753820.2014 .908580$

\title{
LO BARROCO EN LA TELEVISIÓN FRANQUISTA: TIPOS Y TEMAS; ACTORES Y ESCENARIOS.
}

\author{
JULIO MONTERO Y MARÍA ANTONIA PAZ. \\ Universidad Complutense de Madrid.
}

Se aborda aquí ${ }^{1}$ qué temas, autores y obras de nuestro Barroco se presentaron en Televisión Española (desde ahora TVE) durante el franquismo, su encuadramiento y evolución. Se ha revisado la programación día a día y se han visionado las fuentes ${ }^{2}$. Hemos analizado los aspectos más evidentes del Barroco: personajes, obras y hechos históricos. Los resultados de las búsquedas se ofrecen en el anexo 1: son 42 emisiones, ninguna anterior a 1967.

Este periodo coincide básicamente con Manuel Fraga (1962-1969) y Sánchez Bella en el Ministerio de Información y Turismo (1969-1974). Durante el mandato del primero se puso en marcha la segunda cadena (el UHF) y se potenció la presencia de España en el exterior. El segundo extiende más ampliamente su mandato para nuestro caso particular y afirmó en $Y a$, que "la tarea en educación popular ha de ser, sobre todo, contribuir a la creación de ese 'hombre español nuevo', ancho de miras y superador de particularismos. Una labor incansable de difusión (...) En este sentido creo que requiere especial atención la televisión, cuya incidencia en la formación del hombre crea en nuestros días una eminente responsabilidad en quienes tienen a su cargo su rectoría"3. En definitiva, no hay dudas sobre el convencimiento entre los gobernantes franquistas sobre la importancia de la televisión como instrumento de educación social. Eso no significa que las orientaciones fluyeran desde la cúspide al último profesional del TVE sin obstáculos para los planes (si los hubiera habido fuera de esa definición general). Cada guionista, cada realizador, cada director, cada profesional (menos en el área de informativos) se encontraba a diario en la situación de moverse en un área estrecha marcada por los límites de la escasez y la censura y en esa zona desarrollaba lo que podía de sus ideas, visión del mundo, deseos y esperanzas en lo político, cultural e, incluso, religioso.

Como se verá los dos grandes bloques en los que aparece el Barroco casi se ajustan a estos dos mandatos: 1967 a 1970 el primero y 1972 a 1974 el segundo. En el primero no faltan reminiscencias del slogan de la apertura turística que impulso Fraga: "Conozca usted España". En el segundo comienzan a vislumbrarse -dentro de un

\footnotetext{
${ }^{1}$ Este artículo recoge resultados del proyecto de investigación TELEVISION Y CULTURA POPULAR DURANTE EL FRANQUISMO: PROGRAMACION, PROGRAMAS Y CONSUMO TELEVISIVO (1956-1975) de ref. HAR2011-27937 y se ha realizado dentro del Grupo Complutense de Investigación HISTORIA Y ESTRUCTURA DE LA COMUNICACIÓN Y EL ENTRETENIMIENTO.

${ }^{2}$ Se realizaron dos tipos de búsquedas. La primera en una base de datos elaborada desde la programación diaria de la Segunda cadena de TVE recogida por la prensa (en concreto La Vanguardia y $A B C$, debidamente contrastadas). Es la más completa de las existentes. Agradecemos a su autor, Juan Martín Quevedo, las facilidades en su utilización. La segunda en la base de datos de TVE (Arca) que contiene los que realmente se conservan y pueden visionarse. 1980), 5 .

${ }^{3}$ Cit. por J. García, Radiotelevisión y politica cultural durante el franquismo (Madrid: CSIC,
} 
panorama fuertemente tradicionalista- rasgos de apertura a la producción de hispanistas (en historia especialmente) ajenos a la cultura oficial de entonces.

La bibliografía no ha prestado apenas atención a la programación de televisión española de entonces, ni menos aún al contenido de sus programas ${ }^{4}$. Salvo Palacio y algunas otras investigaciones recientes, la mayor parte se apoyan en la memoria de los autores, en la prensa de la época y en algunas secuencias aisladas que circulan en internet. Faltan estudios basados en el visionado y análisis de los programas, lo que convierte algunas aportaciones en simples ensayos o comentarios periodísticos.

\section{La evolución de la representación de lo Barroco en Televisión Española: desde los inicios hasta 1970}

Los actores y escenarios del Barroco que presenta Televisión Española se agrupan en dos periodos bien definidos. El primero corresponde a los años 1967 a 1970. Los programas con referencias a nuestro tema son relativamente pocos: Teatro de siempre, presenta ocho entregas; Ateneo, concentra siete; Libros que hay que tener ofreció cinco y el resto se presentan en programas sueltos en Estudio 1 (dos entregas) y una en La víspera de nuestro tiempo (en su primera edición) ${ }^{5}$.

La referencia más amplia al Barroco la conforman las retransmisiones de obras de teatro producidas por TVE en sus estudios o como fruto de una colaboración con las instituciones que pretendieron rehabilitar el corral de comedias de Almagro (Teatro de siempre). Este programa fue el que más frecuentemente acogió autores barrocos. Está presente en la programación de la Segunda Cadena desde su inicio ${ }^{6}$. Los otros dramáticos que emitieron obras de autores barrocos fueron Comedia del humor que lo hizo con La dama duende (Tirso); y Hora $11^{8}$ con Los tres maridos burlados (también de Tirso). Ya en la Primera cadena Estudio 1, montó como gran producción El gran teatro del mundo de Calderón, a cargo de Juan Guerrero Zamora uno de sus directores más destacados ${ }^{9}$.

Los dramáticos de la Segunda cadena se han definido como uno de los aspectos más creativos de ésta ${ }^{10}$. Las realizaciones que nos ocupan aquí, sin embargo, fueron

${ }^{4}$ Algunas excepciones son las publicaciones de Manuel Palacio (Historia de la Televisión en España, 2005) y las de Josep María Baget que escribió en 1993 Historia de la televisión en España (1956-1975) -su tesis doctoral- y en 1999, Quaranta anys de televisió a Cataluña (1959-1999), además del artículo "La cultura a la televisió", en L'Avenç: Revista de història i cultura. Lorenzo Díaz (Historia de la televisión en España 1954-1995) hizo un acercamiento desde la intrahistoria. Jesús García abordó la política cultural en radiotelevisión durante el franquismo, en especial a programas educativos, mientras que Sira Hernández se ha centrado en los programas de divulgación histórica. José Carlos Rueda ha comentado en parte una selección incompleta que se editó en VHS de Crónicas de un pueblo.

${ }^{5} \mathrm{~S}$. Hernández, La historia contada en televisión. El documental televisivo de divulgación histórica en España (Barcelona: Gedisa, 2008), 101 y 107. El programa se dedicó a Quevedo y cerró la serie. Hubo luego otra serie de divulgación histórica con el mismo título.

${ }^{6}$ Fue semanal. Primero los lunes (hasta 1967), luego los jueves, viernes y otros. Siempre en Prime Time. Desapareció en diciembre de 1971. Volvió dos meses después, de forma fluctuante, hasta diciembre de 1972. Duraba unos 90 minutos.

${ }^{7}$ Comedia de humor comenzó a emitirse en enero de 1967 y se canceló en abril de 1968. Duraba 60 minutos, los domingos, y comenzaba a las 20,30. (La proyección que nos ocupa fue el 22.X.1967)

${ }^{8}$ Hora 11 empezó a emitirse en abril de 1968 los domingos a las 11 de la noche. Fue uno de los más longevos. Se mantuvo hasta febrero de 1974 en esa franja horaria, aunque a lo largo de los años varió de día. Duraba unos 60 minutos. (La proyección que nos ocupa fue el 26.X.1970)

${ }^{9}$ Palacio, Historia de la televisión..., 147, que lo sitúa en 1969, según nuestra base de datos fue emitida el 26.III.1970.

${ }^{10}$ Palacio, Historia de la televisión ..., 131-133. 
versiones clásicas de obras clásicas. Calderón es el autor más representado. La dama duende, La vida es sueño y El Gran teatro del mundo constituyen sus tres obras más vistas en la pequeña pantalla. El segundo es Tirso: El condenado por desconfiado (la más representada de su repertorio), seguida de Don Gil de las calzas verdes y Marta la piadosa (ver Tabla 1 en el anexo).

Ateneo es el siguiente programa que más aportaciones sobre nuestros autores ${ }^{11}$. Se componía de tres partes: primero, una exposición, generalmente de arte actual; seguía con el comentario de tres personas - una de ellas el autor- sobre una obra literaria, con frecuencia recién publicada; y se cerraba con una escena de teatro. Hubo menciones a Quevedo en dos ocasiones; a Tirso en una con motivo de la representación de El condenado por desconfiado y, sobre todo, a Calderón de la Barca, con representaciones de La dama duende, El gran teatro del mundo y La vida es sueño (en dos ocasiones). Puede decirse que su público eran las minorías cultas (novedades sobre exposiciones, teatro y libros).

El tercer gran contenedor de emisiones sobre el Barroco de esta primera etapa fue Libros que hay que tener. ${ }^{12}$ Cada entrega se planteaba de manera independiente. Un experto daba continuidad al capítulo. Se alternaban imágenes con voces en off que recitaban textos, preferentemente poesías, de los autores. Se centraba en uno de los libros del autor tratado. Desde ahí se abordaban rasgos biográficos. Con frecuencia algunos expertos charlaban sobre la obra escogida. De hecho, estableció un elenco básico de obras españolas de siempre. Se producía en colaboración entre la Comisaría de Extensión Cultural del Ministerio de Educación y Ciencia ${ }^{13}$. Esto da idea de su carácter divulgativo.

Una serie documental de divulgación cultural e histórica ${ }^{14}$ fue La víspera de nuestro tiempo, que comenzó a emitirse en abril de 1967. La dirigió Jesús Fernández Santos y en ella colaboraron jóvenes cineastas que ya habían trabajado para la Segunda cadena. Se trataba de dar a conocer autores españoles -inicialmente del siglo XIX y $\mathrm{XX}$, de ahí el nombre de la serie- y situarlo en su contexto histórico-cultural y humano $^{15}$. La serie se cerró en enero de 1969 con un episodio dedicado precisamente a Francisco de Quevedo ${ }^{16}$.

El catálogo de programas que recogieron algún aspecto del Barroco se cierra con el único de estos años dedicado a la pintura y a Diego Velázquez: La Paleta de Velázquez, (emitido el 26 de agosto de 1969) dentro de la serie Medio siglo de imagen ${ }^{17}$. Es llamativa esta escasez de referencias a la pintura de nuestro Siglo de Oro que

${ }^{11}$ Tuvo una presencia muy prolongada: del 21 de noviembre de 1966 al 7 de noviembre de 1970 . El programa tenía entre 25 y 30 minutos de duración. Cada uno de los temas tenían una duración de unos 10 minutos. De 1967 a 1969 se emitió sobre todo los viernes y variaba entre las 22:00 y las 23:45. Progresivamente se retrasó. Por ejemplo, entre principios y octubre de 1970 se emitió los miércoles a las 21:45. Sus cuatro últimas emisiones fueron sábados a las 22:30.

${ }_{12}$ De abril de 1967 a noviembre de 1968. Era semanal y de 15 minutos de duración.

${ }^{13}$ Así lo señalan los títulos de crédito del material visionado.

${ }^{14}$ Sobre el documental de divulgación histórica vid. S. Hernández Corchete, "Hacia una definición del documental de definición histórica", Comunicación y Sociedad, XVII: 2, (2004), 89-123, (p.121).

${ }^{15}$ Baget Herms, Historia de la televisión..., 175-176.

${ }^{16}$ S. Hernández, La historia contada ...,100-103. Lo dirigió Antonio Mercero.

${ }^{17}$ Inició su emisión en octubre de 1968 los lunes a las 22:02. Terminó en octubre de 1969. Se mantuvo en la franja de las diez de la noche, con cambio de día, aunque sus tres últimas entregas fueron los jueves a las 21:00. Duraba 30 minutos. 
probablemente habrá que poner en relación con las dificultades de producción de la Segunda cadena ${ }^{18}$.

Estas emisiones dan cuenta de una idea fundamental: no hay un tratamiento específico de lo barroco en la Televisión Española de aquellos años. Sí que existen rasgos trazados con independencia: se abordan autores y obras literarias. Apenas hay referencias más allá de éstos. Si se atiende exclusivamente al Barroco, podría decirse que TVE presentó unos actores sin escenarios, sin contexto cultural, estético, o más en general, histórico. Estaríamos ante un conjunto de referencias independientes y diversas. Unas recorren las representaciones teatrales, que sitúan al espectador ante versiones de piezas literarias clásicas. Esta sobrerrepresentación de los autores dramáticos barrocos quizá deba situarse en las limitaciones de producción que presentaba TVE y que trataban de evitar problemas con la censura y con los derechos de autor ${ }^{19}$. En el fondo ideología y escasez de recursos. Por otra parte la solución era una vía digna para los profesionales. Los autores barrocos -junto a Lope- constituían el teatro español popular por excelencia. Su trasposición a aquel presente no era una mala solución.

Junto a las representaciones están los comentarios de expertos sobre determinados libros de estos mismos autores (casi siempre, salvo en el caso de Quevedo y Góngora, obras de teatro también). En medio de todo, como en una isla, una apelación al genio de la pintura de la época, Velázquez. Elementos sueltos de un conjunto que se evita mencionar y dentro de las posibilidades de producción -económicas y de censuraque ofrecía la época, como se ha señalado.

En realidad no es el Barroco lo que importa, ni siquiera cualquier otro movimiento estético. En estos años lo que interesa, especialmente para la Segunda cadena, es ofrecer una imagen de España que atraiga turistas. No es ajeno a este hecho la relación con el festival de teatro de Almagro que ya se ha mencionado. Tampoco la colaboración con el Ministerio de Educación con la fijación de un canon de nuestros clásicos de la literatura (en este caso el peso relativo de los autores barrocos cayó significativamente). Hay que tener en cuenta que en el nacimiento de la Segunda Cadena estuvo presente como su primer director el que dirigiera precisamente el programa Conozca usted España de finalidad bien precisa ${ }^{20}$. Incluso la gran producción El gran teatro del mundo, se encuadra -de otra manera- en este empeño por dar a conocer lo mejor de nuestro país, también de la capacidad de TVE, a ser posible con la obtención de premios internacionales que los avalasen ${ }^{21}$.

\section{La audiencia de estos programas}

Los datos de audiencia disponibles para este periodo están en una encuesta de $1969^{22}$. En términos de audiencia el programa de mayor éxito fue Estudio 1. Probablemente la obra de Calderón El Gran teatro del mundo consiguiera cerca de 8 millones de espectadores.

\footnotetext{
${ }^{18}$ En general los profesionales de la radio como de la televisión hacían malabarismos para lograr el escaso margen de creatividad que permitían los exiguos presupuestos de unas arcas diezmadas. J. García, Radiotelevisión y política cultural..., 494.

${ }^{19}$ Jesús García señala que la serie Novela se centraba en el siglo XIX por esos mismos motivos. No parece arriesgado traspasar a los autores del barroco esa lógica. J. García, Radiotelevisión y política cultural durante el franquismo, 567.

${ }^{20}$ Palacio, Historia de la televisión...,126.

${ }^{21}$ Palacio, Historia de la televisión..., 147.

${ }^{22}$ La audiencia de televisión en España (Madrid: Imprenta del Ministerio de Información y Turismo, 1969).
} 
La Segunda cadena la conectaban algo más de la mitad de los televidentes en las provincias de Madrid, Toledo, Barcelona y Zaragoza. El segundo bloque de asiduos (entre el 49 y el 30\%) se situaba en el País Vasco, Navarra, la Galicia litoral, Segovia, Valladolid y Palencia y una aislada Sevilla en Andalucía. Esto da cuenta de una realidad: toda Extremadura, Andalucía (salvo Sevilla), Castilla La Mancha, el litoral levantino excepto Barcelona, toda Castilla y León (salvo las tres mencionadas) y Cantabria y Asturias vivían la margen de la Segunda cadena, y por lo tanto de los programas que se han mencionado aquí. Puede afirmarse de manera rotunda el carácter minoritario de esta cadena ${ }^{23}$.

Es relevante comparar los máximos de audiencia para las dos cadenas. El de la Primera lo consiguió un concurso con algo más de 10 millones. En la segunda fueron dos series norteamericanas: La conquista del espacio (Star Treck) y Arresto y juicio: con medias de 725 mil y 825 mil espectadores cada una. Catorce y doce veces menos respectivamente. Si comparamos por géneros, los dramáticos más cuidados de la Primera (Estudio 1) alcanzaron 7 millones trescientos mil espectadores. Teatro de siempre, el más importante de la Segunda, llegó a 328 mil: 23 veces menos. En realidad son dos líneas de flujo televisivo absolutamente diversas, casi dos televisiones distintas. La Segunda para núcleos urbanos (mayoritariamente grandes ciudades y alrededores: Madrid y Toledo, Barcelona y Zaragoza de manera clara).

La mayor parte de los programas que nos interesan entre 1967 y 1970 fueron emitidos de 9,30 a 11,30 de la noche. Nuestros cálculos desde los datos desglosados sitúan las cifras de espectadores en una media de 445 mil para los días de lunes a viernes ${ }^{24}$.

Los datos de audiencia sobre los programas que incluyeron referencias al Barroco, tuvieron escasa incidencia. Sólo uno de ellos (Teatro de siempre) consigue ser el más visto en la Segunda cadena el día de su emisión. El resto se sitúan detrás (no sabemos con qué cifras) ${ }^{25}$. No son siquiera programas de mayorías en el canal minoritario. En la medida en que muchos se mantuvieron bastantes años en antena hay que pensar que alguna valoración positiva merecerían, aunque quizá fuera solo su bajo coste de producción. Sobre estos datos minoritarios hay que situar la excepción de Estudio 1 en 1969 y que superaría con seguridad la media habitual por ser una gran producción y por la fuerza de la autopromoción consiguiente: El gran teatro del mundo, de Calderón en montaje de Juan Guerrero Zamora.

En resumen: el Barroco en Televisión Española llegó, sólo a partir de 1967, a una población muy reducida, mediante programas para minorías en una cadena minoritaria, con una excepción: la audiencia millonaria de Calderón en una gran producción dramática para concurso en festivales internacionales de televisión y emitida por la primera cadena. Probablemente estas menguadas cifras se adecuaban a unos objetivos modestos pero bien definidos: la población urbana sería la primera en descubrir el turismo, interior por supuesto, y no era mala opción centrar en ella los escasos recursos disponibles para difundir una idea de nuestra cultura en paralelo a la que correspondía -sobre todo- a paisajes, sol, monumentos históricos, museos, etc. No era el Barroco lo que más importaba difundir; pero algunos de sus autores constituían referentes imprescindibles. Esos referentes no faltaron en el diseño general de la cultura española que se ofrecía divulgada y con los limitados recursos disponibles de TVE y, especialmente, de su Segunda Cadena.

\footnotetext{
${ }^{23}$ La audiencia..., 14.

${ }^{24}$ La audiencia..., 13

${ }^{25}$ La audiencia..., 23-32
} 


\section{Una nueva etapa: lo barroco en la televisión española en 1972 y en 1974.}

Si los autores dramáticos y sus obras constituyeron la parte más destacada del Barroco en las pantallas de televisión hasta 1970, puede decirse que luego casi desaparecen. Es difícil explicar esta ausencia. Los dramáticos continuaron su estela de éxitos y de innovación, pero en 1974 aumentaron mucho las emisiones de películas y telefilmes (937 horas). Fue el segundo bloque, después de los informativos (que ocuparon 1.000 horas) en 1974 y con más del doble que las de cultura y religiosas (392) y las deportivas $(580)^{26}$. Calderón, Góngora, Tirso y Quevedo ocuparán cada uno un programa de la serie Hoy hablamos de...; pero no tendremos ni una sola representación de sus obras en los dramáticos.

Lo que se ha de destacar es la irrupción de los pintores españoles del Prado. Frente a una única aparición de Velázquez antes de 1974, en ese año desfilaron los grandes del Barroco por la pantalla en la serie Los pintores del Prado. La primavera de aquel año, fue la de los nuestros pintores: Velázquez, el 24 de abril; Zurbarán, el 22 de mayo y Ribera, Murillo y Rubens, los días 6, 12 y 26 de junio respectivamente. Si se tiene en cuenta que en fechas muy próximas se emitieron programas de Hoy hablamos de... referidos a escritores del Barroco (Quevedo, Góngora, y otro documental breve sobre Quevedo, además de uno sobre Tirso) nos encontraremos, aunque fuera en la Segunda cadena, ante una concentración de emisiones sobre un tema poco frecuente en TVE. El último elemento destacable es que en 1972 se ofrece por fin un contexto general sobre el Barroco español: de ello se encargó una serie de divulgación histórica: La noche de los tiempos.

La noche de los tiempos (Primera cadena 1971-1972) ${ }^{27}$ era una emulación de la serie británica Civilización. Se dedicaron tres episodios al Siglo de Oro y uno a la decadencia de España durante el siglo XVII. Estas entregas se emitieron en pleno verano $^{28}$. Se pueden presuponer que las siguieron menos personas que durante el resto del año, aunque TVE estuviera interesada por la serie en general ${ }^{29}$. Parte de su material se recicló luego en otros programas.

La segunda serie que abordó temas y personajes del Barroco fue Los pintores del Prado $^{30}$, ya citada. Aunque se grabaron dramatizaciones históricas, han de entenderse como ficciones o quizá como ensayos históricos audiovisuales ${ }^{31}$.

${ }^{26}$ García, J., Radiotelevisión y politica cultural..., 595.

${ }^{27}$ Era un relato divulgativo sobre la historia de España. Asesorada por catedráticos de universidad, aunque los guionistas se empeñaron en que llegara al público. Una voz en off narraba -con alguna dramatización- y las imágenes -tomas actuales de edificios o elementos de la época- ilustraban. Cada capítulos duraba 30 minutos.

${ }^{28} 21$ y 28 de julio y el 4 y el 11 de agosto de 1972.

${ }^{29}$ Por ejemplo, se rodó en color y en $35 \mathrm{~mm}$ (Baget, Historia..., p. 240 y Hernández, La historia.., pp. 113 y 120).

${ }^{30}$ En una versión oficial (3500 programas para la educación. RTVE, Madrid: Servicio de publicaciones del Ente Público RTVE, 1987, 119-120), Televisión Española, muchos años después, definía así la serie: "Tomada como fundamento la obra del pintor al que se dedica el episodio, se narra audiovisualmente la génesis del cuadro tomado como referencia y se recrea el ambiente de su época, en interpretación de actores que reconstruyen la circunstancia del artista, en la que aparecen personajes coetáneos que sitúan el momento histórico y su personalidad." En nuestra opinión y después de visionar los capítulos correspondientes, la descripción es exacta, aunque el predominio de la ficción en las reconstrucciones es patente. Este mismo aspecto lo destacan otros autores (Hernández, La Historia contada...,115; Palacio, Historia de la Telelvisión..., 129 y Baget, Historia de la televisión...,281).

${ }^{31}$ El director de la serie fue Ramón Gómez Redondo. Cada episodio lo realizaron directores y guionistas diversos. El encargado del guión para el capítulo de Velázquez fue probablemente el mejor especialista español de entonces en el pintor: Julián Gállego. En los que aquí nos ocupan colaboraron 
La tercera serie que abordó personajes (Quevedo, Tirso de Molina y Góngora) y temas (El Siglo de Oro) relevantes para este trabajo fue Hoy hablamos de... ${ }^{32} \mathrm{El}$ programa lo presentaba Rafael Penagos, un habitual de los espacios culturales en Televisión Española por aquellos años ${ }^{33}$.

En resumen: en este segundo periodo, Televisión Española ofreció, mediante el documental histórico, un primer contexto de lo Barroco. Para la cultura oficial de entonces lo realmente valiosos y destacable era el Siglo de Oro. El Barroco constituía casi un accidente ya que las realizaciones más brillantes de la cultura española se habían retrasado al producirse durante una época de decadencia política y ruina económica. En cualquier caso, la serie La noche de los tiempos ofreció un relato bastante completo (4 capítulos) de nuestro tema. En la medida en que se mencionaban los protagonistas literatos, sobre todo dramaturgos, y pintores- puede considerarse cumplida la tarea de la contextualización no realizada hasta entonces. La serie se emitió en la Primera cadena. Quienes hubieran seguido los documentales en Prime Time de la Primera también podían optar por algunos de los de la segunda. Un programa de Hoy hablamos de... se dedicó al Siglo de Oro. Recogió en su reportaje inicial 12 minutos del capítulo correspondiente a la serie de la Primera. En fin: aunque tarde, el Barroco mereció una contextualización y un tratamiento general. Se presentó como una parte de un todo más importante: nuestro Siglo de Oro, que se consideró como lo verdaderamente valioso. La segunda idea es la desaparición de nuestro clásicos barrocos de los dramáticos de producción propia de Televisión. La tercera, la apertura al mundo de la pintura barroca -en realidad a la barroca del Prado- en un formato original que mezcla ficción y realidad.

\section{Los escenarios y los actores del barroco español en Televisión Española (1956- 1975)}

La noche de los tiempos fue el programa que hizo el diseño más completo y ajustado a las líneas oficiales del momento (1972) del escenario del Barroco español. La serie lo presentó como una combinación de ficciones y realidades, de obras artísticas y realidades sociales, de referencias a los hechos políticos y a su interpretación desde una perspectiva tradicionalista. Esta amalgama se presenta en un discurso, en perfecta coherencia con la política cultural oficial, que ve en la época imperial española el culmen de nuestra historia y el modelo hacia el que hay que tender. Esta consideración es difícil no relacionarla con aquel presente. El telespectador podía percibirlo así: esta

Francisco Regueiro, director de cine (Zurbarán y Murillo); Manuel Matji, también director de cine (Rubens) y Manuel Marinero, guionista y crítico de cine (Ribera). El programa se emitía en la franja de las diez de la noche los miércoles: Prime Time en la cadena minoritaria.

${ }^{32}$ En antena desde noviembre de 1973 a enero de 1975. Hasta enero del 74 duró 60 minutos. Luego se redujo a la mitad. Tras la breve presentación, el programa ofrecía un reportaje con imágenes y una voz en off. Habitualmente aprovechaba materiales anteriores (en los de El siglo de oro emplearon los de La noche de los tiempos). Duraba unos 12-15 minutos. Luego se iniciaba un coloquio con especialistas. Por ejemplo en el caso de Tirso de Molina, muy centrado en su teatro, se reunieron Víctor Ruiz Iriarte (autor dramático); Lorenzo López Sancho (escritor) y Manuel Dicenta (actor). Esta parte completaba el programa. Empezó a emitirse los martes a las 22:00. Cambió de día varias veces (lunes, domingo, miércoles y viernes). Su presupuesto debió ser muy bajo por el constante reciclaje de materiales anteriores. El programa ni siquiera se menciona en la bibliografía académica hasta la fecha.

${ }^{33}$ Premio Nacional de Poesía en 1964, presentador de televisión, actor de doblaje y actor. Antes había dirigido el espacio nocturno Versos a media noche con el que pretendía "que la poesía [...] llegue a las casas y se aposente en ellas de un modo sentimental" (cit. por J. García, Radiotelevisión y política cultural, 266-267) 
fue la mejor época de nuestra historia. Si imitamos -con las adaptaciones consiguienteslo que entonces se hizo, y si asumimos su valores, podremos alcanzar de nuevo un nivel similar.

Es significativo el encuadre general ${ }^{34}$ : una dramatización presenta a Felipe II camino de El Escorial. Sabe que va a morir. Su oración a Dios es "tanta grandeza, tanto poderío y me negáis un hijo Señor que sepa gobernarlos." Tras su muerte, la voz en off apostilla, para alejar cualquier duda: "junto a este imperio material, había edificado otro imperio: el del espíritu”. De ahí el auge espectacular de la cultura española coincidiendo con "la decrepitud del poder político en los reinados de Felipe III y Felipe IV." La declaración es clara: al monarca más grande de la historia de España hay que atribuirle la grandeza cultural, artística y científica que hubo a su muerte en nuestro país. Por si quedara alguna duda el narrador dirá enseguida que el origen del Siglo de Oro está en la unidad de España conseguida por Fernando e Isabel. No hay dudas sobre el contexto y origen de nuestra grandeza. El texto vuelve a subrayar: "Máximo apogeo de las artes, letras y ciencias españolas. Acababa de empezar el Siglo de Oro. Es la hora de España en todo el mundo" y todo ello en un espectacular crescendo de la banda sonora.

Los Austrias menores, una desgracia para España, se encontraron sencillamente con algo que no era suyo. Unos hijos torpes malgastaron una herencia enorme en lo político y en lo cultural. Este empeño por mantener líneas de continuidad entre lo que se considera que mejor refleja la grandeza española con la estética del Barroco se manifiesta también en elementos de carácter circunstancial. Por ejemplo, una voz que quiere ser la de Herrera, ante El Escorial afirma: "Yo sé que estas líneas llegarán a cansar al ojo que las mira" y, por si algún espectador no reparara en la imagen, la voz en off apostilla: "sin saberlo, Juan de Herrera, estaba hablando del Barroco."35

Los protagonistas de este escenario son variados: "Don Quijote, Velázquez, Garcilaso, Cervantes, inician su obra. Juan de Arce, san Juan de la Cruz, santa Teresa, san Ignacio y, el escultor Gregorio Fernández, nace el pícaro, personaje original en la literatura mundial, antes teólogos, juristas y humanistas dictan teorías universales, se fundan misiones en América..." Hay realidad y ficción; pero también yuxtaposición de nombres y saberes para dar la ida de acumulación enorme en su cantidad y excelencia. Es una transición narrativa para descender al análisis que se realiza en los capítulos II y III y en el siguiente dedicado a la Hora del crepúsculo.

Dos años después Rafael Penagos utilizó esas mismas imágenes para introducir su programa Hoy hablamos de... Cambió el comentario de los invitados ${ }^{36}$ sobre los motivos de la decadencia: se criticó la actitud de defensa a ultranza del catolicismo en Europa, la escasez de inversiones en industria, que condujeron a la ruina económica, etc. Se abría una línea explicativa absolutamente diversa que completarían sobradamente las explicaciones sobre los pintores españoles.

El tema argumental de la segunda entrega de la serie se centra en el protagonismo de España en la Contrarreforma. "El Barroco había nacido en Trento" dice el narrador. La voz omnisciente del documental recordará que el auge espiritual que tocó vivir a Felipe IV nada tuvo que ver con su gobierno. El pueblo español acertaba con su intuición, en la religiosidad popular y en la espiritualidad de los santos, con la misión que le correspondía y que podía asumir solo, sin ayuda de sus torpes reyes. El paso siguiente es manifestar cómo nuestros genios de la pintura y de la escultura supieron asumir esa sensibilidad popular. Nuestros pintores e imagineros

\footnotetext{
${ }^{34}$ Texto del capítulo El siglo de oro I, de la serie La noche de los tiempos.

35 Texto del capítulo El siglo de oro II, de la serie La noche de los tiempos.

${ }^{36}$ Diego Angulo, catedrático de Historia del Arte; Fernando Díaz-Plaja, catedrático de Literatura y Antonio Gala, escritor.
} 
absorbían ese espíritu y lo plasmaron con su genio. El Greco, Velázquez y Zurbarán se presentan como la tríada fundamental en este proceso. A ellos se añaden Murillo y Ribera. Llama la atención que El Greco y Zurbarán se presenten como superiores a Velázquez; pero desde la perspectiva religiosa y sentido utilitarista del arte para favorecer la devoción popular esta clasificación tiene su lógica. Además de que Velázquez es un pintor de corte... y de la de Felipe IV. No deja de sorprender el duro trato que se da a estos reyes ya en 1972, cuando ya se había proclamado al entonces Príncipe Juan Carlos sucesor de Franco como rey.

La tercera entrega se centra en la literatura barroca. De nuevo la conexión con los grandes: Cervantes y Lope de Vega. De hecho la dramatización de este episodio recoge el expurgue de libros de la biblioteca del viejo hidalgo y se consigna un aspecto de interés para el resto del capítulo: se queman los de caballerías que constituyen lo ajeno a lo español, lo quimérico, lo que aleja del realismo de nuestro arte. El capítulo casi se convierte en una lección de literatura en la que se repasan autores, obras y temas. Se explica un personaje fundamental de nuestra literatura: el pícaro. Se mencionan las obras fundamentales y aparecen imágenes de sus ediciones de época. Incluso el texto establece una conexión entre el realismo popular español y la evolución del pícaro en la ficción: "Lazarillo nace con el imperio español, Guzmán y otros bajo el signo de la desilusión política y social de una época." En cualquier caso, constituyen, dice el narrador, "la primera piedra de la novela realista que se acaba de inventar." Después se presentan los temas y autores dramáticos. Primero Lope y luego sus sucesores barrocos: Calderón y Tirso. Y los personajes del desconfiado y Don Juan. Y repaso de los poetas y narradores y ensayistas y místicos... se cierra con una poesía religiosa que casi todos los españoles de entonces conocían, al menos habían escuchado: "No me mueve mi Dios para quererte/el cielo que me tienes prometido..."

Un panorama en el que el Barroco se presenta desdibujado, como una parte no muy bien definida de ese Siglo de Oro grandioso. La siguiente entrega de la misma serie (La hora del crepúsculo) entra más a fondo en el tema que nos ocupa. Presenta un escenario político desastroso. Felipe III hace renacer las rencillas cortesanas y se rodea de incapaces más atentos a las apariencias y a su propio beneficio que al bien de España. El siguiente Felipe era un pobre irresoluto. El Conde-Duque de Olivares no consiguió que los catalanes participaran en los gastos de la política imperial... Difícil era hacer una selección de males peores para el franquismo, que presumía de todo lo contrario. Unos reyes y unos gobernantes despreocupados de sus súbditos y un pueblo que ha asumido la grandeza imperial y vive en ella con dignidad a pesar de su miseria.

En este contexto se presenta el Barroco como arte popular: se cita al Marqués de Lozoya: "El Barroco hispánico es el resultado de dos factores: la pobreza y el anhelo de magnificencia". Es la resistencia a la decadencia: como el pueblo español, grandilocuente y generoso, lleno de vida y exuberante de color. El Barroco es un arte popular en el sentido de dirigirse al pueblo, no a las minorías intelectuales. Es una evasión popular colectiva, dirá el narrador.

Un escenario simplificado separa lo Barroco del aquel Siglo de Oro y deja para éste lo más vinculado a la peor decadencia política y a sus consecuencias. Lo Barroco correspondería a una sensibilidad más populachera que popular. Frente a él, el Siglo de Oro se presenta vinculado también a elementos populares, pero más limpios. Una cultura centrada en dar cuenta del carácter religioso y popular de las mejores realizaciones estéticas españolas de la historia; preparadas por buenos gobernantes y que sus sucesores dilapidaron. El mantenimiento de esos valores en el pueblo español ajeno a su decadencia y a la política- hicieron posible que los mejores espíritus creativos 
en las artes, en las letras y en la religiosidad los asumieran y realizaran desde ellos sus mejores obras... naturalmente para asombro de la humanidad de todos los tiempos.

Tras delimitar el escenario es preciso atender a los actores. En primer lugar, Quevedo, al que se dedicaron dos programas que reciclaron parte de un antiguo material $^{37}$. El documental de 1973 comienza con Erase un hombre a una nariz pegado. Se atiende de manera somera al contexto histórico, pero hay más referencias a hechos que a ofrecer explicaciones: "La Corte se instaló en Valladolid tras la muerte de Felipe II... La Corte regresa a Madrid..." o " tras unas aventuras cortesanas y pendencieras por las que tuvo que refugiarse en el campo, se marchó a Sicilia". Se percibe que la historia de España está cambiando a peor: "Ha muerto Felipe III y el poder está en manos del Conde Duque de Olivares". Quevedo critica la corrupción de costumbres con "Páginas acertadas y quejumbrosas de una España que quiere ver de otra manera" . "El origen de todo mal estaba en la política que llevaba el valido", no se culpa a la Monarquía. Se reconstruyen sus últimos días en prisión y su regreso a Madrid. Pero la narración se centra en el hombre, no en el contexto: "A punto de cumplir 60 años, se siente fatigado, la prisión ha debilitado su cuerpo, muere lentamente...”. En cualquier caso, Quevedo da cuenta de una España que no funciona, de un país en crisis.

En 1974 se le dedicó un programa en la serie Hoy hablamos de... Se volvió a reutilizar el material de La víspera de nuestro tiempo con un nuevo comentario de tono novelesco. Se mencionan sus enfrentamientos con Góngora y se le califica de "poeta de la muerte y la vida". Luego todo fueron opiniones de especialistas sobre su producción literaria $^{38}$ : se le caracteriza como un creador de lenguaje y de conceptos. Se habla entonces del Barroco y de su influencia posterior: en Eugenio D'Ors ("que lo haya reconocido la gente, es otra cosa") y en Valle Inclán ( "su retórica efectiva tan española es continuada por Valle Inclán"). Igualmente sobre sus escritos políticos y su paternidad sobre el humor negro. También se establece algún paralelismo con Cervantes: "El Buscón es un libro de picaresca y a la vez una burla del género, como El Quijote". De nuevo ha desaparecido el contexto en un diálogo de especialistas en literatura.

También Góngora tuvo su retrato televisivo en Hoy hablamos de... Se le presenta como un hombre culto e inteligente ${ }^{39}$. Un hombre discutido y calumniado, satirizado como pocos, objeto de las críticas de Lope y de Quevedo. Para los invitados, especialmente para Joaquín Entrambasaguas, cierra el Renacimiento. Su obra más importante es neorrenacentista, no barroca. Lo barroco aparece sólo en las canciones de tipo popular. Góngora renueva la poesía del Renacimiento (ya no es el modelo perfecto del Barroco lírico español como se había dicho en años anteriores) y si no tuvo seguidores fue porque "nadie es capaz de imitar su técnica". De nuevo el primer plano de los especialistas dejo un fondo sin pintar.

Uno de los pocos autores cuya vida se presenta en un marco histórico bien definido es Tirso de Molina. En Hoy hablamos de... Tirso de Molina (1974) la monarquía de los Austrias aparece con todas sus contradicciones "consumida en ideales de batallas y conquistas" (se elude la palabra decadencia). También se sitúa a la figura del Don Juan en la época de la Contrarreforma y del luteranismo. El largo destierro de Tirso en Trujillo, Salamanca y Toledo se explica por su "afición a atacar a prohombres

${ }^{37}$ Quevedo, emitido en 1973, de 11 minutos de duración, reproduce la parte final, con variaciones, y en Hoy hablamos de .... Quevedo.

${ }^{38}$ Presenta Rafael de Penagos e intervienen en el debate: Pedro de Lorenzo, escritor; Félix Ros, poeta y catedrático de literatura; Domingo Fernández Barreira, periodista.

${ }^{39}$ Intervinieron, además de Rafael de Penagos, Joaquín de Entrambasaguas, catedrático de literatura en la Universidad Complutense de Madrid, José García Nieto, poeta y Federico Sainz de Robles, escritor y crítico literario. 
de la época". El Burlador de Sevilla es su obra más mencionada. El coloquio se centra en las aportaciones de Tirso al teatro español. A juicio de los invitados, son tres: la diversidad, es capaz de escribir El condenado por desconfiado y Don Gil de las calzas verdes, por ejemplo. Luego, el acierto de incorporar a las mujeres en protagonistas con personalidad propia, y finalmente la creación de un personaje universal, Don Juan, muy imitado y recreado después. Tirso no es barroco, es "un fraile postconciliador, con gracia y desvergüenza".

En fin: un programa centrado en el coloquio de especialistas sobre autores literarios del Barroco volcado más en precisiones técnicas que en un empeño de divulgación y sin apenas referencias al contexto político, social, económico y cultural del momento, como ya estaban ofreciendo otros relatos televisivos, en la misma cadena sobre los años del Barroco.

El patrón general sobre nuestros pintores barrocos señala la decadencia económica de aquella España. El país pasaba por una seria penuria. Lo afirma Velázquez en conversación con Zurbarán ${ }^{40}$; le aprietan esas mismas dificultades al Spagnoleto $^{41}$ y a Murillo ${ }^{42}$. A Zurbarán le recomiendan que parta para América y que pinte allí para evitar las pesadillas que le torturan por la escasez de encargos ${ }^{43}$. Pero los soldados españoles que regresan de América y se encuentran en Nápoles con Ribera y Quevedo en una taberna no parece que hayan conseguido mucho allí: apretados a preguntas reconocen que solo un gallo de pelea... y dan gracias a Dios por haber regresado $^{44}$. América aparece en esta serie sobre los pintores barrocos españoles como un problema, no como una solución. El problema sin embargo es español y los trazos que lo definen en estas entregas parecen traducir las conclusiones de Hamilton ${ }^{45}$ y los Chaunu ${ }^{46}$ sobre los desastrosos efectos económicos de las importaciones descontroladas de metales preciosos por la monarquía española: hundimientos de la industria, de la ganadería y de la agricultura y establecimiento de costumbres entre la nobleza que nos alejaron de los inicios modernos del capitalismo europeo.

No se trata de un relato coordinado. De hecho cada episodio se encargó a un realizador distinto, como ya se ha señalado. Estamos más bien ante unos rasgos coincidentes al presentar cada personaje, cada pintor, en su escenario propio y común lógicamente a los del barroco. Sobre este elemento común se construyó una visión negativa propia, excepto en el caso de Velázquez, que puede entenderse como la historia de un triunfo personal (la nobleza del pintor plasmada en su mortaja con el hábito de Santiago) que refleja el de un oficio que ya empieza a ser considerado como un ejercicio artístico y así lo reconoce la autoridad del monarca ${ }^{47}$. También se vuelve sobre este asunto, la grandeza de la pintura, en el episodio de Ribera. Aquí el maestro insiste a uno de sus discípulos: "la grandeza de la pintura depende de la responsabilidad de los pintores". Es un grito a la responsabilidad del genio y del gremio, cuando antes se ha advertido que los poderosos quieren utilizar el arte para beneficio propio (desde su

\footnotetext{
40 "La nobleza de la pintura", en la serie Los pintores del Prado (1974)

41 "Ribera, el explorador en las tinieblas", en Los pintores ... (1974)

42 "La Virgen niña”, en Los pintores ... (1974)

43 "Ribera, el explorador en las tinieblas", en Los pintores... (1974)

44 Íbidem

${ }^{45}$ Earl J. Hamilton, El tesoro americano y la revolución de los precios en España. 1501-1650 (Barcelona: Crítica, 2000). La primera edición inglesa es de 1934, pero la Guerra Civil y las dificultades posteriores dificultaron su difusión en España. La primera traducción de los artículos que componen el obro es de 1948.

${ }^{46}$ Pierre Chaunu, Séville et l'Atlantique , 1504-1650 ( París: SEVPEN, 12 volúmenes, 1955-1960)

47 "La nobleza de la pintura", en la serie Los pintores ... (1974)
} 
vanidad a sus aventuras políticas o de simple dominio sobre la gente sin privilegios), con propósitos ajenos desde luego a lo que deben mover a los artistas de verdad ${ }^{48}$.

En general -y salvo el caso de Velázquez- la pintura es negra, sobre todo en lo que se refiere a la religiosidad. En un caso hay una burla de la virginidad: la hija de Murillo es seducida por un pícaro y sus deseos de ser monja se retratan como algo artificial y propio solo de una niña que desconoce el mundo, que no ha madurado ${ }^{49}$. En el caso de Ribera es un poderoso (Don Juan José de Austria) quien seduce a la hija del pintor. En este caso se explicita que el hecho hundió anímicamente al artista por lo que tenía de deshonra para toda la familia.

Esa crítica a la religión se desvela más ampliamente en el episodio de Zurbarán en un fuerte claroscuro que enfrenta la blancura de los hábitos de los cartujos con las negras pesadillas del artista: un irlandés se flagela por encargo de un noble para sustituir la penitencia que deben los pecados de la joven; y una madre busca desconsolada a su hija convertida en cerdo por un demonio. La ignorancia, la superstición conforman ese negro que se opone a la blancura de los lienzos del sevillano... y de su religión ${ }^{50}$.

En fin. Un Siglo de Oro no mencionado y dibujado con aguafuertes notables. Han desaparecido las metáforas de años anteriores que buscaban en la esencia del pueblo español -católico y fiel reflejo de la grandeza perdida por los gobernantes- y de sus artistas la grandeza de sus creaciones. La bibliografía moderna -la de la crisis económica provocada por la importancia masiva de metales preciosos que hundieron industria, ganadería y agricultura de Castilla- parece haber barrido la cultura oficial del periodo 1967 a 1970.

\section{Conclusiones}

Los autores del Barroco que, por un motivo u otro, aparecen en Televisión Española entre 1967 y 1975 son exclusivamente los más conocidos por el gran público. Probablemente no sea más que una consecuencia de entender la cultura popular como una divulgación de la alta cultura.

El repaso de los autores y temas que se presentan tienen interés. El primer elemento que hay que destacar es que no ha habido respuestas a la búsqueda Barroco. Nos encontramos, por tanto, ante una utilización de elementos que se presentan en otro contexto, que nos hablan de otra cosa. No hay un espacio para el Barroco en la televisión franquista. Sus personajes -solo algunos de ellos- se sitúan en otro escenario. En este sentido es muy llamativo que sólo de Francisco de Quevedo se afirme su inclusión en este movimiento. De Tirso, Góngora y Calderón incluso se les considera como parte de otras sensibilidades literarias en afirmaciones realizadas por especialistas. No tiene que ver con la centralidad de los personajes y el carácter secundario de lo abstracto (los movimientos y las estéticas en general), porque sí se encuentran espacios dedicados nominalmente al romanticismo, o al románico o al gótico. No ha de entenderse esta omisión como efecto de la censura. Sencillamente, el concepto Siglo de Oro, que se menciona de manera abundante y al que se le dedican cinco programas específicos, constituye un referente más popular y más fácilmente comprensible que el de Barroco. Primero porque exigiría la propia ruptura del famoso siglo dorado de nuestra cultura. Segundo, porque cabe presentarlo como una unidad amplia que se puede describir cronológicamente, y por tanto con continuidad, tan importante en

\footnotetext{
48 "Ribera, el explorador en las tinieblas", en Los pintores ... (1974)

49 "Murillo. La Virgen Niña, en la serie Los pintores... (1974)

50 "La humilde luz de un sueño", en la serie Los pintores... (1974)
} 
televisión. En tercer lugar, porque lo peor de nuestra historia (según la historiografía oficial de la época), el reinado de Carlos II quedaba fuera de la centuria áurea.

Si se organizan las emisiones en televisión sobre estos autores hasta el 31 de diciembre de 1975, puede observarse que prácticamente todos pertenecían a programas de teatro (realizados en los estudios de Televisión Española, o grabadas in situ y luego emitidas), de presentación y comentario de libros (Libros que hay que tener), o sobre autores (Hoy hablamos de...) o temas culturales (Ateneo). Si a estos se añaden tres series documentales (La víspera de nuestro tiempo, La noche de los tiempos y Los pintores del Prado) casi todo queda encuadrado. El escenario en que se situó a nuestros actores barrocos fue el mundo de la cultura española de siempre. De hecho, uno de los espacios teatrales en que más obras de Tirso y Calderón se representaron se titulaba precisamente Teatro de siempre y el referido a los libros no abordaba novedades editoriales, sino obras maestras de la literatura española: esos eran los libros que había que tener. Algo parecido puede afirmarse de los pintores, los únicos artistas plásticos de nuestro Barroco a los que se presta atención. Velázquez, Murillo, Zurbarán, Ribera y el propio Rubens entran en la serie Los pintores del Prado. Su referente es la pinacoteca, no su época. Es más, la realización de cada capítulo atiende a aspectos decididamente personales de sus biografías, no a cuestiones de contextualización estética o histórica más general.

Los años del Barroco -entendido al margen, cronológico también, del siglo de oro- carecían del interés político que el régimen otorgaba a la España imperial de los Austrias mayores. Más aún, se situaba en unos años de decadencia y pérdida de la hegemonía internacional de España y de profunda crisis económica. Sólo los autores literarios y los pintores constituían un timbre de honor para aquellos tiempos. Quizá por eso los programas de televisión se centraron en ellos (en sus vidas, en sus obras) y no en su época y en su contexto histórico más amplio, hasta tal punto que se acabó cerrando el Barroco en los años finales del último Austria. Y entonces se presentó como una concepción popular sana que decidió asumir un pueblo, abandonado de sus reyes y gobernantes, que buscó el consuelo en la apariencia, en la fiesta, en el teatro y en la religiosidad popular. Sin la capacidad de construir en sillar recio, nuestra cultura cubrió la pobreza del ladrillo con estuco, volutas y dorados. Así la veía el Marqués de Lozoya y así lo asumió Televisión Española, muy probablemente sin caer en la cuenta de ello. 
Anexo. Tabla1. Programas emitidos en Televisión Española sobre autores y temas del Barroco (1956-1975)

\begin{tabular}{|c|c|c|c|c|c|c|}
\hline \multirow{7}{*}{$\begin{array}{l}\text { Tema/Autor } \\
\text { Quevedo }\end{array}$} & Cadena & Fecha & Emisión & Programa & Duración & Horario $^{51}$ \\
\hline & UHF & 29.XI.1968 & $\begin{array}{l}\text { D. Francisco } \\
\text { de Quevedo }\end{array}$ & Ateneo & 30 & $\begin{array}{l}\text { Prime } \\
\text { Time }\end{array}$ \\
\hline & UHF & 6.XII.1968 & $\begin{array}{l}\text { D. Francisco } \\
\text { de Quevedo }\end{array}$ & Ateneo & $30^{\prime}$ & Noche \\
\hline & UHF & 3.I. 1969 & $\begin{array}{l}\text { Recuerdo a } \\
\text { Quevedo }\end{array}$ & $\begin{array}{l}\text { La víspera de } \\
\text { nuestro } \\
\text { tiempo }\end{array}$ & $21.15^{\prime}$ & $\begin{array}{l}\text { Prime } \\
\text { Time }\end{array}$ \\
\hline & UHF & 12.VI.1969 & $\begin{array}{l}\text { Burlas, } \\
\text { sueños y } \\
\text { alegorías }\end{array}$ & $\begin{array}{l}\text { Teatro de } \\
\text { siempre }\end{array}$ & $42^{\prime}$ & $\begin{array}{l}\text { Prime } \\
\text { Time }\end{array}$ \\
\hline & UHF & 5.III.1974 & Quevedo & $\begin{array}{l}\text { Hoy } \\
\text { hablamos de }\end{array}$ & $30^{\prime}$ & $\begin{array}{l}\text { Prime } \\
\text { Time }\end{array}$ \\
\hline & UHF & 7.V.1974 & Quevedo & Documental & 5 & Tarde \\
\hline \multirow[t]{10}{*}{$\begin{array}{l}\text { Tirso de } \\
\text { Molina }\end{array}$} & UHF & 9.III.1967 & $\begin{array}{l}\text { D. Gil de las } \\
\text { calzas } \\
\text { verdes }\end{array}$ & $\begin{array}{l}\text { Teatro de } \\
\text { siempre }\end{array}$ & 1h $27^{\prime}$ & $\begin{array}{l}\text { Prime } \\
\text { Time }\end{array}$ \\
\hline & UHF & 13.X.1967 & $\begin{array}{l}\text { El } \\
\text { condenado } \\
\text { por } \\
\text { desconfiado }\end{array}$ & $\begin{array}{l}\text { Teatro de } \\
\text { siempre }\end{array}$ & 1h $16^{\prime}$ & $\begin{array}{l}\text { Prime } \\
\text { Time }\end{array}$ \\
\hline & UHF & 25.V.1967 & $\begin{array}{l}\text { El burlador } \\
\text { de Sevilla }\end{array}$ & $\begin{array}{l}\text { Libros que } \\
\text { hay que tener }\end{array}$ & $15^{\prime}$ & $\begin{array}{l}\text { Prime } \\
\text { Time }\end{array}$ \\
\hline & UHF & 21.VIII.1967 & $\begin{array}{l}\text { El burlador } \\
\text { de Sevilla }\end{array}$ & $\begin{array}{l}\text { Libros que } \\
\text { hay que tener }\end{array}$ & $15^{\prime}$ & $\begin{array}{l}\text { Prime } \\
\text { Time }\end{array}$ \\
\hline & UHF & 15.IX.1967 & $\begin{array}{l}\text { Marta la } \\
\text { piadosa }\end{array}$ & $\begin{array}{l}\text { Teatro de } \\
\text { siempre }\end{array}$ & $1 \mathrm{~h} 34^{\prime}$ & $\begin{array}{l}\text { Prime } \\
\text { Time }\end{array}$ \\
\hline & UHF & 8.X.1970 & $\begin{array}{l}\text { El } \\
\text { condenado } \\
\text { por } \\
\text { desconfiado }\end{array}$ & Ateneo & $30^{\prime}$ & $\begin{array}{l}\text { Prime } \\
\text { Time }\end{array}$ \\
\hline & UHF & 26.IX.1970 & $\begin{array}{l}\text { Los tres } \\
\text { maridos } \\
\text { burlados }\end{array}$ & Hora 11 & $44.29^{\prime}$ & $\begin{array}{l}\text { Prime } \\
\text { Time }\end{array}$ \\
\hline & UHF & 9.X.1974 & $\begin{array}{l}\text { Tirso de } \\
\text { Molina }\end{array}$ & $\begin{array}{l}\text { Hoy } \\
\text { hablamos de }\end{array}$ & $27.57^{\prime}$ & $\begin{array}{l}\text { Prime } \\
\text { Time }\end{array}$ \\
\hline & $\begin{array}{l}1^{\mathrm{a}} \\
\text { CADENA }\end{array}$ & Sin fecha & $\begin{array}{l}\text { D. Gil de las } \\
\text { calzas } \\
\text { verdes }\end{array}$ & Estudio 1 & $1 \mathrm{~h} 05^{\prime}$ & $\begin{array}{l}\text { No } \\
\text { localizado }\end{array}$ \\
\hline & $\begin{array}{l}\text { Quizás 1 } \\
\text { CADENA }\end{array}$ & Sin fecha & $\begin{array}{l}\text { El } \\
\text { condenado } \\
\text { por }\end{array}$ & $\begin{array}{l}\text { Retransmisión } \\
\text { desde el } \\
\text { Teatro }\end{array}$ & 1h $46^{\prime}$ & $\begin{array}{l}\text { No } \\
\text { localizado }\end{array}$ \\
\hline
\end{tabular}

${ }^{51}$ De $14 \mathrm{~h}$ a $17 \mathrm{~h}$. Sobremesa; $17 \mathrm{~h}$ a 21h. Tarde; $21 \mathrm{~h}$. A 23h. Prime Time; 23 h. En adelante, Noche. 


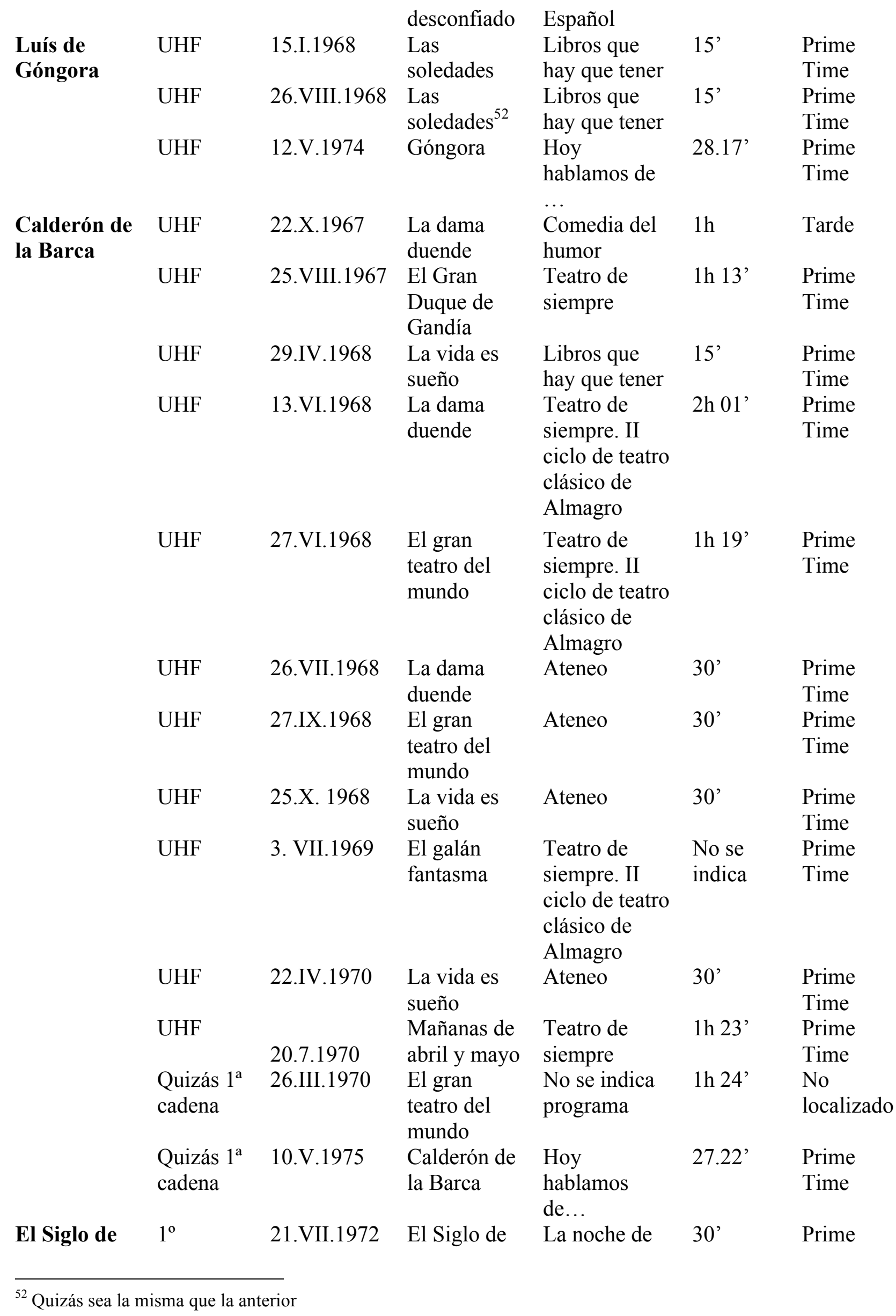




\begin{tabular}{|c|c|c|c|c|c|c|}
\hline \multirow[t]{5}{*}{ Oro } & \multicolumn{2}{|l|}{ CADENA } & Oro 1 & \multicolumn{2}{|l|}{ los tiempos } & \multirow{3}{*}{$\begin{array}{l}\text { Time } \\
\text { Prime } \\
\text { Time }\end{array}$} \\
\hline & $1^{\mathrm{o}}$ & 28.VII.1972 & El Siglo de & La noche de & $30^{\prime}$ & \\
\hline & CADENA & & Oro 2 & los tiempos & & \\
\hline & & 4.VIII.1972 & El Siglo de & La noche de & 30 & Prime \\
\hline & CADENA & & Oro 3 & los tiempos & & Time \\
\hline \multirow{6}{*}{$\begin{array}{l}\text { La hora del } \\
\text { crepúsculo } \\
\text { Las Indias } \\
\text { Occidentales }\end{array}$} & $1^{\mathrm{o}}$ & 11.VIII.1972 & La hora del & La noche de & $30^{\prime}$ & Prime \\
\hline & CADENA & & crepúsculo & los tiempos & & Time \\
\hline & $1^{\mathrm{o}}$ & 27.V.1972 & Las Indias & La noche de & $30^{\prime}$ & Prime \\
\hline & CADENA & & $\begin{array}{l}\text { Occidentales } \\
1\end{array}$ & los tiempos & & Time \\
\hline & $1^{\mathrm{o}}$ & 3.VI.1972 & Las Indias & La noche de & $30^{\prime}$ & Prime \\
\hline & CADENA & & $\begin{array}{l}\text { Occidentales } \\
2\end{array}$ & los tiempos & & Time \\
\hline \multirow{3}{*}{$\begin{array}{l}\text { Diego } \\
\text { Velázquez }\end{array}$} & UHF & 26.VIII.1969 & La paleta de & Medio siglo & $30^{\prime}$ & Prime \\
\hline & & & Velázquez & de imagen & & Time \\
\hline & $\mathrm{UHF}^{53}$ & 24.IV.1974 & $\begin{array}{l}\text { La nobleza } \\
\text { en la pintura }\end{array}$ & $\begin{array}{l}\text { Los pintores } \\
\text { del Prado }\end{array}$ & 28 & Noche \\
\hline Zurbarán & UHF & 22.V.1974 & $\begin{array}{l}\text { Zurbarán: la } \\
\text { humilde luz } \\
\text { de un sueño }\end{array}$ & $\begin{array}{l}\text { Los pintores } \\
\text { del Prado }\end{array}$ & $29^{\prime}$ & Noche \\
\hline \multirow{2}{*}{$\begin{array}{l}\text { Bartolomé } \\
\text { Esteban } \\
\text { Murillo }\end{array}$} & UHF & 12.VI.1974 & $\begin{array}{l}\text { Murillo: la } \\
\text { virgen niña }\end{array}$ & $\begin{array}{l}\text { Los pintores } \\
\text { del Prado }\end{array}$ & 30 & Noche \\
\hline & & & & & & \\
\hline \multirow{2}{*}{$\begin{array}{l}\text { José de } \\
\text { Ribera }\end{array}$} & UHF & 5.VI.1974 & Ribera: el & Los pintores & $29^{\prime}$ & Noche \\
\hline & & & $\begin{array}{l}\text { explorador } \\
\text { de las } \\
\text { tinieblas }\end{array}$ & & & \\
\hline Rubens & UHF & 26.VI.1974 & $\begin{array}{l}\text { Rubens: la } \\
\text { osadía de } \\
\text { vivir }\end{array}$ & $\begin{array}{l}\text { Los pintores } \\
\text { del Prado }\end{array}$ & $27^{\prime}$ & Noche \\
\hline
\end{tabular}

\footnotetext{
${ }^{53}$ La base de datos de TVE (ARCA) lo señala como emitido en la Primera Cadena
} 